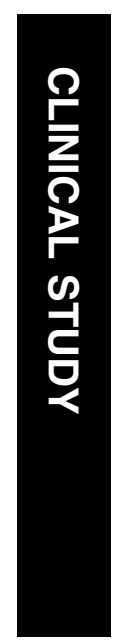

${ }^{1}$ Ministry of Health, Ankara Diskapi Yildirim Beyazit Training and Research Hospital, Department of Ophthalmology, Ankara, Turkey

${ }^{2}$ Suleyman Demirel University, Faculty of Medicine, Department of Ophthalmology, Isparta, Turkey

${ }^{3}$ Ministry of Health, Ankara Training and Research Hospital, Department of Ophthalmology, Ankara, Turkey

Correspondence: U Acar, Ministry of Health, Ankara Diskapi Yildirim Beyazit Training and Research Hospital, Department of Ophthalmology, Kazakistan Caddesi No: 90/7,

Emek-Ankara, Turkey Tel: + 903122125361 or 905057977618 ;

Fax: 903123186690 . E-mail: druguracar@gmail. com

Received: 13 July 2010 Accepted in revised form: 18 November 2010 Published online: 21 January 2011

We confirm that the manuscript, or parts of it have not been and will not be submitted elsewhere for publication

\title{
A new ocular trauma score in pediatric penetrating eye injuries
}

\begin{abstract}
Purpose To assess the prognostic value of a new ocular trauma score (OTS) in pediatric penetrating injuries.

Methods Children $\leq \mathbf{1 5}$ years of age that presented to the emergency room with penetrating eye injuries between April 2007 and August 2008 were evaluated prospectively. All patients were reviewed on the basis of age, gender, time of injury and how it happened, time of admission, time of surgery, type of penetrating injury, initial and final visual acuity (VA), and concomitant eye pathology. Injuries were classified based on a new OTS, and we assessed the relationship with final VA and the new OTS.
\end{abstract}

Results In total, 30 eyes in 29 patients (41.38\% female, $58.62 \%$ male) with a mean age of $6.83 \pm 4.00$ years (range: 1-15 years) were included in the study. Initial VA, which was evaluated in 22 patients, was as follows: no light perception (NLP) in 2 (9.09\%) patients, light perception (LP) to hand motion (HM) in $8(36.36 \%)$ patients, counting fingers in $6(27.27 \%)$ patients, $0.1-0.5$ in $4(\mathbf{1 8 . 1 8 \%})$ patients, and $\geq 0.6$ in $2(9.09 \%)$ patients. Final VA, which was evaluated in 27 patients, was as follows: NLP in $3 \mathbf{( 1 1 . 1 1 \% ) ~ p a t i e n t s , ~}$ LP to HM in $3(\mathbf{1 1 . 1 1 \% )}$ ) patients, counting fingers in $2(7.41 \%)$ patients, $0.1-0.5$ in 11 (40.74\%) patients, and $\geq 0.6$ in $8(29.63 \%)$ patients. The relationship between initial VA and final VA was statistically significant $(P<0.001)$.

Conclusions The new OTS calculated at initial examination may be of prognostic value in children with penetrating eye injuries. Eye (2011) 25, 370-374; doi:10.1038/eye.2010.211; published online 21 January 2011

Keywords: ocular trauma score; penetrating eye injuries; ocular trauma
U Acar ${ }^{1}$, OY Tok ${ }^{2}$, DE Acar ${ }^{3}$, A Burcu ${ }^{3}$ and F Ornek ${ }^{3}$

\section{Introduction}

Worldwide, ocular trauma is an important cause of eye morbidity and is a leading cause of non-congenital monocular blindness in children. ${ }^{1-4}$ Eye trauma constitutes $7 \%$ of all bodily injuries and 10-15\% of all eye disease. ${ }^{5,6}$ The severity of trauma is directly proportional to morbidity and affects the socioeconomic loss; however, this loss can be prevented if certain precautions are taken. ${ }^{7}$ In industrialized nations, eye injury has become the most frequent cause of hospitalization of ophthalmological patients. ${ }^{8}$ In the United States, eye injuries are the second most frequent cause of presentation for ocular treatment in pediatric cases, following strabismus. , $9,10^{-10}$

The importance of eye trauma has increased because of the relatively high rate of trauma in the pediatric age group. Various studies have reported that $20-50 \%$ of ocular injury admissions are children. ${ }^{11-13}$

Using the eye injury registry databases of the United States and Hungary, Kuhn et al ${ }^{9}$ developed the ocular trauma score (OTS) in 2002, a simplified categorical system for standardized assessment and visual prognosis in ocular injuries (Table 1).

This study aimed to assess the prognostic value of a pediatric penetrating ocular trauma score (POTS) in pediatric penetrating injuries, and to analyze the epidemiological and clinical characteristics, and results of eye trauma.

Patients and methods

The records of children aged $\leq 15$ years that were presented with penetrating eye injuries between April 2007 and August 2008, were evaluated prospectively. Patients that were previously operated on once, were followed-up at another hospital and had another eye disease 
Table 1 Original OTS variables and scoring ${ }^{9}$

\begin{tabular}{lc}
\hline Variables & Raw points \\
\hline Initial visual acuity & \\
No light perception & 60 \\
Light perception/hand motion & 70 \\
$1 / 200-19 / 200$ & 80 \\
$20 / 200-20 / 50$ & 90 \\
$<20 / 40$ & 100 \\
Rupture & -23 \\
Endophthalmitis & -17 \\
Perforating injury & -14 \\
Retinal detachment & -11 \\
Afferent pupillary defect & -10 \\
\hline
\end{tabular}

were excluded from the study. All patients were reviewed on the basis of age, gender, time of injury, and mechanism of injury, time of admission, time of surgery, type of penetrating injury, initial visual acuity (VA), and final VA (measured 1 year following the trauma) and concomitant eye pathology. Injuries were classified based on a new OTS, named POTS. And we assessed the relationship to final VA and the POTS.

All patients were treated with repair surgery and were followed-up regularly. All open globe injuries are categorized by the open globe classification system into three anatomical zones. ${ }^{4,10}$ Zone I includes the cornea and limbus, zone II is 5-mm posterior to the limbus, and zone III, which includes the macula and optic nerve, is posterior to zone II.

The POTS used in this study scored VA lower than the OTS does, based on our consideration of the probability of obtaining false initial VA scores or the inability to obtain VA scores in children $\leq 15$ years of age. Likewise, relative afferent pupillary defect (RAPD) could not be evaluated in most of the cases in this study and was therefore not included in the scoring. Patient variables, such as age and wound location, were considered important parameters and were included in the scoring (Table 2). The patients were divided into five groups (higher points is presumed to be better prognosis) based on the trauma evaluation score:

Group 1: $<45$ points.

Group 2: 46-64 points.

Group 3: 65-79 points.

Group 4: 80-89 points.

Group 5: 90-100 points.

The following equation was used to determine the trauma score in patients for whom an initial VA was not obtained:

$$
2 \times(\text { age }+ \text { zone })-\text { corresponding pathologies }
$$

Statistical analysis was performed with SPSS v.15.0 software (SPSS, Inc., Chicago, IL, USA). Categorical
Table 2 Calculating the POTS and raw points in this study

\begin{tabular}{lc}
\hline Variables & Raw points \\
\hline Initial visual acuity & \\
NLP & 10 \\
LP/HM & 20 \\
Counting fingers & 30 \\
$0.1-0.5$ & 40 \\
$0.6-1.0$ & 50 \\
& \\
Age of the pediatric patients (years) & \\
$0-5$ & 10 \\
6-10 & 15 \\
11-15 & 25 \\
& \\
Wound location & \\
Zone I & 25 \\
Zone II & 15 \\
Zone III & 10 \\
Concomitant eye pathologies & \\
Iris prolapse & \\
Hyphema & -5 \\
Organic/unclean injury & \\
Delay of surgery ( $>48 \mathrm{~h})$ & -5 \\
Traumatic cataract & -5 \\
Vitreous haemorrhage & -5 \\
Retinal detachment & -10 \\
Endophthalmitis & -20 \\
\hline
\end{tabular}

Abbreviations: HM, hand motion; LP, light perception; NLP, no light perception; POTS, pediatric penetrating ocular trauma score.

variables were tested with the Kruskal-Wallis $\chi^{2}$-test. A $P$-value $<0.05$ was considered statistically significant.

Approval of the study was obtained from the institutional review board and all patients' parents provided informed consent. The study and data collection protocols conformed to all local laws, and complied with the principles of the Declaration of Helsinki.

\section{Results}

In total, 30 eyes in 29 patients (12 (41.38\%) female, $17(58.62 \%)$ male) with a mean age of $6.83 \pm 4.00$ years (range: 1-15 years) were included in this study. In all, $14(48.28 \%)$ of the patients injured their right eye, $14(48.28 \%)$ injured their left eye and 1 patient $(3.44 \%)$ had bilateral injuries. Her central corneal thickness was $275 / 290 \mu$ and she was diagnosed as Ehlers-Danlos type VIB, so she was not included from the statistical analysis.

The observed injuries were often caused by sharp objects, such as knives (16.67\%), glass (13.33\%), and scissors (10.0\%) (Table 3). Mean elapsed time from injury to presentation was $10.10 \pm 12.50$ hours 
(range: 30 min-3 days) and mean elapsed time from presentation to surgery was $8.69 \pm 5.34$ hours (range: 3-20 h). Penetrating eye injuries were primarily to the cornea in 20 eyes $(66.67 \%)$, the corneosclera in 7 eyes $(23.33 \%)$, and the sclera in 3 eyes $(10.0 \%)$.

Initial VA, which was evaluated in $22(78.57 \%)$ patients, was as follows: No light perception (NLP) in $2(9.09 \%)$ patients, light perception (LP) to hand motion (HM) in $8(36.36 \%)$ patients, counting fingers in $6(27.27 \%)$ patients, $0.1-0.5$ in $4(18.18 \%)$ patients, and $\geq 0.6$ in $2(9.09 \%)$ patients (Table 4$)$.

Table 3 The cause of penetrating eye injuries

\begin{tabular}{lc}
\hline Causes of injury & $\begin{array}{c}\text { Number of cases } \\
(\%) \mathrm{n}=30\end{array}$ \\
\hline Knife & $5(16.67 \%)$ \\
Glass & $4(13.33 \%)$ \\
Scissors & $3(10.0 \%)$ \\
Pencil & $2(6.67 \%)$ \\
Toys & $2(6.67 \%)$ \\
Stone & $2(6.67 \%)$ \\
Iron & $2(6.67 \%)$ \\
Cup & $2(6.67 \%)$ \\
Sparkler & $2(6.67 \%)$ \\
Wire & $2(6.67 \%)$ \\
& \\
Others & \\
Finger & $1(3.33 \%)$ \\
Bough & $1(3.33 \%)$ \\
Nail & $1(3.33 \%)$ \\
Tack & $1(3.33 \%)$ \\
\hline
\end{tabular}

Table 4 Initial and final visual acuity in the patients

\begin{tabular}{llc}
\hline & \multicolumn{2}{c}{ Number of cases (\%) } \\
\cline { 2 - 3 } & $\begin{array}{c}\text { Initial visual } \\
\text { acuity } \mathrm{N}=22\end{array}$ & $\begin{array}{c}\text { Final visual } \\
\text { acuity } \mathrm{N}=27\end{array}$ \\
\hline No light perception & $2(9.09 \%)$ & $3(11.11 \%)$ \\
Light perception/hand motion & $8(36.36 \%)$ & $3(11.11 \%)$ \\
Counting fingers & $6(27.27 \%)$ & $2(7.41 \%)$ \\
$0.1-0.5$ & $4(18.18 \%)$ & $11(40.74 \%)$ \\
$\geq 0.6$ & $2(9.09 \%)$ & $8(29.63 \%)$ \\
\hline
\end{tabular}

The distribution of penetrating eye injuries was as follows: $8(26.67 \%)$ patients had hyphema, $13(43.33 \%)$ had iris prolapse, $13(43.33 \%)$ had traumatic cataract, $3(10.0 \%)$ had retinal detachment, $3(10.0 \%)$ had eyelid laceration, and $1(3.33 \%)$ had vitreous haemorrhage.

All primary surgeries were concerned with reconstitution of globe integrity, with repositioning or excision of the ocular contents.

Final VA, which was evaluated in 27 (96.43\%) patients, was as follows: NLP in $3(11.11 \%)$ patients, LP to $\mathrm{HM}$ in $3(11.11 \%)$ patients, counting fingers in $2(7.41 \%)$ patients, $0.1-0.5$ in $11(40.74 \%)$ patients and $\geq 0.6$ in $8(29.63 \%)$ patients (Table 4$)$. During the follow-up period, five $(16.67 \%)$ patients resulted in phthisis bulbi.

The relationship between initial VA and final VA was statistically significant $(P<0.001)$ and the POTS obtained at initial examination may be of prognostic value in children with penetrating eye injuries $(P<0.001)$ (Table 5). This result shows that higher POTS is related to better prognosis.

\section{Discussion}

Eye injury remains a common and preventable cause of blindness throughout the world. ${ }^{3,4}$ Despite public health campaigns designed to prevent eye injuries, open globe injuries still occur. Identifying the causes and the nature of these injuries in the population, and directing educational and legislative efforts towards minimizing eye injury, are the previous goals of prevention. ${ }^{14}$

In addition to visual impairment, eye injury is known to cause significant morbidity, in terms of pain, psychosocial stress, and economic burden. ${ }^{15}$ The annual cost of work-related eye injury is estimated to be 1-3 billion dollars in the United States. ${ }^{15}$ The classification of eye trauma is useful for ophthalmologists, and provides simple and enhanced communication about particular patient features. ${ }^{10,16}$ It is also helpful for predicting the final visual outcome and the need for rehabilitation services in patients with severely injured eyes. ${ }^{17}$

Table 5 Final Visual Acuity outcomes based on POTS

\begin{tabular}{lcccccc}
\hline Sum of raw points & Group & $\begin{array}{c}\text { Number of } \\
\text { eyes }(\mathrm{n}=27)\end{array}$ & NLP & $\begin{array}{c}\text { LP/HM } \\
\text { fingers }\end{array}$ & $\begin{array}{c}\text { Counting } \\
\text { fingers }\end{array}$ \\
\hline$\leq 45$ & 1 & 7 & 3 & 3 & -0.5 & 1 \\
$46-64$ & 2 & 11 & - & - & 1 & 9 \\
$65-79$ & 3 & 6 & - & - & - & 1 \\
$80-89$ & 4 & 0 & - & - & - & - \\
$90-100$ & 5 & 3 & - & - \\
\hline
\end{tabular}

Abbreviations: HM, hand motion; LP, light perception; NLP, no light perception.

$P<0.001$ (Kruskal-Wallis test). 
In the presented series $58.62 \%$ of the patients were male. Other studies on trauma epidemiology confirm a male predominance, with a male: female ratio varying between 1.25 and 5.5.3,14,18,19 The male: female ratio in this study was 1.42 . This may reflect the more aggressive characteristics of male behaviour even in childhood aged.

Functional prognosis following globe injuries varies widely, from NLP to normal vision. Previous studies on ocular trauma have identified the risk factors associated with poor visual outcome, including initial $\mathrm{VA}^{20-23}$ size, and posterior extent of the wound (zone), ${ }^{4,20-22}$ the presence of an afferent pupillary defect, ${ }^{20}$ type of injury, ${ }^{20,21}$ presence of vitreous hemorrhage, ${ }^{20,21}$ presence of lens damage, ${ }^{20,21}$ presence of retinal detachment, ${ }^{24}$ and the presence of an intraocular foreign body and endophtalmitis. 22,25

The OTS is a scoring system that includes VA at presentation and the extent of ocular trauma, as well as the presence or absence of globe rupture, endophthalmitis, retinal detachment, and relative afferent pupillary defect. A higher OTS score is typically associated with a better prognosis. ${ }^{4,9,19,26}$

In this study we used the POTS in pediatric penetrating eye injuries (Table 2); it is similar to the OTS, but not the same. We classified injuries using that score and assessed relationship of the final VA and the POTS. The trauma score we used awards fewer points for initial VA than the OTS, in consideration of the probability of obtaining false initial VA scores or the inability to obtain VA scores in children $\leq 15$ years of age.

Eye trauma in children differs in many ways from that in adults. It is difficult to obtain sufficient information from children about how trauma occurs and they may not be aware of a reduction in their VA. As such, diagnostic delay increases the risk of endophthalmitis. Even under the best conditions, because of the restlessness of children and communication problems, ophthalmic examination in children is very difficult, as compared with adults.

Visual development continues until the age of 9-10 years, and despite successful trauma treatment VA may not improve because of amblyopia. Traumatic cataract in children $<5$ years of age causing secondary deprivational amblyopia could cause a further decrease in the visual outcomes than just the injury itself.

Even after appropriate diagnosis and treatment, the healing process in children is associated with dense fibrous tissue proliferation, and because of a longer life expectancy in children than in adults it can lead to different visual consequences. In childhood, intraocular surgery may trigger an extensive fibrin reaction that may be another reason for the lower success of keratoplasty in children. ${ }^{27}$ So another reason for low success in the keratoplasty surgery in childhood is that situation. ${ }^{28}$ Obviously, the same trauma in the eye of a child $<5$ years of age and in a patient 15 years of age does not affect the eye in the same manner. As such, in designing this study we considered that age should be a factor included in the scoring system.

The trauma score we designed for pediatric patients with penetrating injury was strongly correlated with the predictability of final VA $(P<0.001)$. As reported in many other studies, the most important factor that affected final VA in this study was initial VA $(P<0.001)$; however, in preverbal children, especially from the affect of the trauma, it was difficult to determine VA, injury time, and shape of the injury. Because of these reasons; especially in the childhood, different classification need was born from the described classification in the literature on the basis VA. For this purpose, multi-center studies with larger series are needed.

\section{Summary}

What was known before

- The classification of eye trauma (OTS) is useful for ophthalmologists, and provides simple and enhanced communication.

What this study adds

- In this study we used the POTS in pediatric penetrating eye injuries; it is similar to the OTS, but not the same. The trauma score we used awards fewer points for initial VA than the OTS, in consideration of the probability of obtaining false initial VA scores or the inability to obtain VA scores in children $\leq 15$ years of age. Patient variables, such as age and wound location, were considered important parameters and were included in the scoring.

\section{Conflict of interest}

The authors declare no conflict of interest.

\section{References}

1 Soylu M, Demircan N, Yalaz M, Isiguzel I. Etiology of pediatric perforating eye injuries in southern Turkey. Ophthalmic Epidemiol 1998; 5(1): 7-12.

2 DeRespinis PA, Caputo AR, Fiore PM, Wagner RS. A survey of severe eye injuries in children. Am J Dis Child 1989; 143(6): 711-716.

3 Rahman I, Maino A, Devadason D, Leatherbarrow B. Open globe injuries: factors predictive of poor outcome. Eye 2006; 20(12): 1336-1341.

4 Knyazer B, Levy J, Rosen S, Belfair N, Klemperer I, Lifshitz T. Prognostic factors in posterior open globe injuries (zone-III injuries). Clin Experiment Ophthalmol 2008; 36(9): 836-841.

5 Parver LM, Dannenberg AL, Blacklow B, Fowler CJ, Brechner RJ, Tielsch JM. Characteristics and causes of 
penetrating eye injuries reported to the National Eye Trauma Registry, 1985-1991. Public Health Rep 1993; 108(5): 625-630.

6 Thylefors B. Epidemiological patterns of ocular trauma. Aust NZ J Ophthalmol 1992; 20(2): 95-98.

7 Serrano JC, Chalela P, Arias JD. Epidemiology of childhood ocular trauma in a northeastern Colombian region. Arch Ophthalmol 2003; 121(10): 1439-1445.

8 Farr AK, Hairston RJ, Humayun MU, Marsh MJ, Pieramici DJ, MacCumber MW et al. Open globe injuries in children: a retrospective analysis. J Pediatr Ophthalmol Strabismus 2001; 38(2): 72-77.

9 Kuhn F, Maisiak R, Mann L, Mester V, Morris R, Witherspoon CD. The Ocular Trauma Score (OTS) Ophthalmol Clin North Am 2002; 15(2): 163-165.

10 Pieramici DJ, Sternberg Jr P, Aaberg Sr TM, Bridges Jr WZ, Capone Jr A, Cardillo JA et al. A system for classifying mechanical injuries of the eye (globe). The Ocular Trauma Classification Group. Am J Ophthalmol 1997; 123(6): 820-831.

11 Thompson CG, Kumar N, Billson FA, Martin F. The aetiology of perforating ocular injuries in children. Br J Ophthalmol. 2002; 86(8): 920-922.

12 Punnonen E. Epidemiological and social aspects of perforating eye injuries. Acta Ophthalmol 1989; 67: 492-498.

13 Moreira CA, Debert-Ribeiro M, Belfort R. Epidemiological study of eye injuries in Brazilian children. Arch Ophthalmol 1988; 106: 781-784

14 Soylu M, Sizmaz S, Cayli S. Eye injury (ocular trauma) in southern Turkey: epidemiology, ocular survival, and visual outcome. Int Ophthalmol 2010; 30(2): 143-148.

15 McGwin Jr G, Hall TA, Xie A, Owsley C. Trends in Eye Injury in the United States, 1992-2001. Invest Ophthalmol Vis Sci 2006; 47: 521-527.

16 Kuhn F, Morris R, Witherspoon CD, Heimann K, Jeffers JB, Treister G. A standardized classification of ocular trauma. Ophthalmology 1996; 103(2): 240-243.
17 Pieramici DJ, Au Eong KG, Sternberg Jr P, Marsh MJ. The prognostic significance of a system for classifying mechanical injuries of the eye (globe) in open-globe injuries. J Trauma 2003; 54(4): 750-754.

18 Soliman MM, Macky TA. Pattern of ocular trauma in Egypt. Graefes Arch Clin Exp Ophthalmol 2008; 246: 205-212.

19 Cillino S, Casuccio A, Di Pace F, Pillitteri F, Cillino G. A five-year retrospective study of the epidemiological characteristics and visual outcomes of patients hospitalized for ocular trauma in a Mediterranean area. BMC Ophthalmol 2008; 8: 6 .

20 Russel SR, Olsen KR, Folk JC. Predictors of scleral rupture and the role of vitrectomy in severe blunt ocular trauma. Am J Ophthalmol 1988; 105(3): 253-257.

21 Hugkulstone CE. Use of a bandage contact lens in perforating injuries of the cornea. JR Soc Med 1992; 85(6): 322-323.

22 Boldt HC, Pulido JS, Blodi CF, Folk JC, Weingeist TA. Rural endopthalmitis. Ophthalmology 1989; 96(12): 1722-1726.

23 Affeldt JC, Flynn Jr HW, Forster RK, Mandelbaum S, Clarkson JG, Jarus GD. Microbial endophthalmitis resulting from ocular trauma. Ophthalmology 1987; 94(4): 404-413.

24 Peyman GA, Carrol CP, Raichand DM. Prevention and management of traumatic endophthalmitis. Ophthalmology 1980; 87(4): 320-324.

25 Hamill MB. Management of scleral perforation. In Krachmer JH, Mannis MJ, Holland EJ (eds) Cornea, Vol. 3 Mosby year book: St Louis, 1997; 1965-1973.

26 Uysal Y, Mutlu FM, Sobacı G. Ocular trauma score in chilhood open-globe injuries. J Trauma 2008; 65(6): 1284-1286.

27 American Academy of Ophthalmolgy: Pediatric Ophthalmology and Strabismus, Vol. 6. San Francisco, AAO, 2005.

28 Farjo AA, Rhee DJ, Soong HK, Meyer RF, Sugar A. Iris-sutured posterior chamber intraocular lens implantation during penetrating keratoplasty. Cornea 2004; 23: $18-28$ 